\title{
A Química na modalidade EJA e no Ensino Médio 'Regular'
}

\author{
Chemistry in EJA modality and it in 'Regular' Secondary School \\ Química en la modalidad EJA y en el Escuela Secundaria 'Regular'
}

Recebido: 31/10/2021 | Revisado: 09/11/2021 | Aceito: 10/11/2021 | Publicado: 16/11/2021

Ivna Di' Moura Oliveira Rodrigues
ORCID: https://orcid.org/0000-0001-7967-1840
Instituto Federal Goiano, Brasil
E-mail: ivnadimoura@ gmail.com
Elisabete Alerico Gonçalves
ORCID: https://orcid.org/0000-0002-2837-3699
Instituto Federal Goiano, Brasil
E-mail: elisabete.alerico@ifgoiano.edu.br
Paulo Vitor Teodoro
ORCID: https://orcid.org/0000-0003-0939-984X
Universidade Federal de Uberlândia, Brasil
E-mail: paulovitorteodoro@ufu.br

\section{Resumo}

Este trabalho tem como objetivo, fazer uma análise comparativa entre o Ensino Médio Regular (EMR) e a Educação de Jovens e Adultos (EJA), no contexto de uma Instituição de ensino público Estadual no Estado de Goiás. O estudo contempla, principalmente, as $3^{\text {a }}$ séries da EJA. Nesse sentido, buscamos compreender se a abordagem no ensino de química para a EJA promove uma aprendizagem significativa quando comparada ao EMR. Como metodologia proposta, foi utilizada a pesquisa qualitativa, exploratória, documental e bibliográfica. Quanto aos procedimentos, realizamos a análise dos Currículos de Referência para o ensino de química em ambas as modalidades, bem como o desenvolvimento e a aplicação de questionários para docentes e estudantes, assim como entrevistas de natureza semiestruturadas com docentes e coordenadores pedagógicos das duas modalidades. Depreendemos, a partir desta pesquisa, que os estudantes da EJA, no contexto em que desenvolvemos esta pesquisa, possuem maior defasagem conceitual quando comparado aos estudantes do EMR. Assim, acreditamos ser condição sine qua nom a adoção de práticas pedagógicas que levem em consideração as particularidades existentes na EJA. Contudo, nas duas modalidades, há necessidade de retomar a discussão sobre as finalidades do ensino de Química, uma vez que esse, da forma que tem sido abordado, tem distanciado os estudantes da real compreensão e objetivo da Química na escola de educação básica.

Palavras-chave: Educação de Jovens e Adultos; Ensino médio regular; Ensino de química.

\begin{abstract}
This paper aims to make a comparative analysis between Regular High School (EMR) and Youth and Adult Education (EJA, in Portuguese), in the context of a State public education institution in the State of Goiás. 3rd series of EJA. In this sense, we seek to understand whether the approach in teaching chemistry to EJA promotes significant learning when compared to EMR. As proposed methodology, qualitative, exploratory, documentary and bibliographic research was used. As for the procedures, we analyzed the Reference Curriculum for teaching chemistry in both modalities, as well as the development and application of questionnaires for teachers and students, as well as semi-structured interviews with teachers and pedagogical coordinators of both modalities. We infer, from this research, that EJA students, in the context in which we developed this research, have a greater conceptual gap when compared to EMR students. Thus, we believe that the adoption of pedagogical practices that take into account the particularities existing in EJA is a sine qua non condition. However, in both modalities, there is a need to resume the discussion about the purposes of teaching Chemistry, since this, as it has been addressed, has distanced students from the real understanding and objective of Chemistry in secondary school.
\end{abstract}

Keywords: Youth and Adult Education; Regular secondary school; Chemistry teaching.

\section{Resumen}

Este trabajo tiene como objetivo realizar un análisis comparativo entre la Educación Secundaria Regular (EMR) y la Educación de Jóvenes y Adultos (EJA), en el contexto de una institución de educación pública estatal en el Estado de Goiás.Tercera serie de EJA. En este sentido, buscamos comprender si el enfoque en la enseñanza de la química a EJA promueve un aprendizaje significativo en comparación con EMR. Como metodología propuesta se utilizó la investigación cualitativa, exploratoria, documental y bibliográfica. En cuanto a los procedimientos, se analizó el Currículo de Referencia para la enseñanza de la química en ambas modalidades, así como la elaboración y aplicación de cuestionarios para docentes y alumnos, así como entrevistas semiestructuradas con docentes y coordinadores 
pedagógicos de ambas modalidades. De esta investigación inferimos que los estudiantes de EJA, en el contexto en el que desarrollamos esta investigación, tienen una brecha conceptual mayor en comparación con los estudiantes de EMR. Así, creemos que la adopción de prácticas pedagógicas que tengan en cuenta las particularidades existentes en EJA es una condición sine qua non. Sin embargo, en ambas modalidades, existe la necesidad de retomar la discusión sobre los propósitos de la enseñanza de la Química, ya que esta, como se ha abordado, ha alejado a los estudiantes de la comprensión y el objetivo real de la Química en la escuela primaria.

Palabras clave: Educación de Jóvenes y Adultos; Escuela secundaria regular; Enseñanza de la química.

\section{Introdução}

A Lei de Diretrizes e Bases da Educação Nacional (LDBEN), n 9.394 (Brasil, 1996), em seu artigo 4. ${ }^{\circ}$, assegura os "padrões mínimos de qualidade de ensino", em consonância com o artigo 206, inciso VII, da Constituição Federal (Brasil, 1988), que trata da garantia do padrão de qualidade da educação como princípio. Além disso, o artigo $4 .^{\circ}$ da LDBEN, também garante a organização da educação básica em três etapas: Educação Infantil, Ensino Fundamental e Ensino Médio. Essas etapas podem ser oferecidas nas modalidades do Ensino regular (ER) ou na Educação de Jovens e Adultos (EJA).

O ER está organizado em anos e séries, atendendo os estudantes sequencialmente, conforme a idade correspondente à Educação Básica (EB). Já a EJA, é uma modalidade da EB que se destina aos jovens e adultos que não tiveram acesso à escolaridade na idade certa ou que, por algum fator, não concluíram os estudos durante o ensino fundamental ou médio. No artigo $37, \S 1^{\circ}$, da LDBEN, está especificado que:

As instituições de educação assegurarão, de forma gratuita, aos jovens e adultos, que não puderam, por algum motivo, estudar na idade regular, oportunidades educacionais apropriadas, consideradas as particularidades do estudante, seus interesses, condições de vida e de trabalho mediante cursos e exames (Brasil, 1996). Apesar da EJA ser uma modalidade de ensino reconhecida pela LDBEN, essa ainda é um campo propício para inúmeras reflexões. Essa modalidade parte de uma longa trajetória que envolve práticas formais e informais,

[...] porque abarca processos formativos diversos, onde podem ser incluídas iniciativas visando à qualificação profissional, o desenvolvimento comunitário, a formação política e um sem número de questões culturais pautadas em outros espaços que não o escolar (Di Pierro, Joia \& Ribeiro, 2001, p. 58).

A EJA, de acordo com o Conselho Nacional de Educação (CNE), vinculado a Câmara de Educação Básica (CEB), apresenta as suas especificidades a partir do Parecer n. ${ }^{\circ}$ 11/2000 (Brasil, 2000). Esse parecer estabelece as diretrizes dessa modalidade de ensino, justificando e direcionando as suas particularidades em relação ao ensino médio regular. Todavia, como destacam Lambarch e Marques (2009), é comum entre os profissionais da Educação, inclusive os professores, concepções de que à modalidade da EJA é uma forma de Ensino Supletivo. Segundo os autores, o Ensino Supletivo teria como função principal a "suplência", que é fundamentada na concepção de educação compensatória a fim de atribuir certificação aligeirada àqueles que não frequentaram a escola em idade regular. Conforme é apresentado no artigo 38, da LDBEN, “os sistemas de ensino manterão cursos e exames supletivos, que compreenderão a base nacional comum do currículo, habilitando ao prosseguimento de estudos em caráter regular”, distinguindo-se da EJA (Brasil, 1996).

Essa visão pode estar elencada ao processo histórico da EJA, pois além de outros programas, desacreditados, o supletivo foi visto como um “[...] mecanismo de "aceleração de estudos" para adolescentes e jovens com baixo desempenho na escola regular" (Di Pierro, Joia \& Ribeiro, 2001, p. 64). Borges Neto (2008) considera que a EJA, no Brasil, acaba por “reexclui-se no presente o excluído do passado" (Borges Neto, 2008, p.7). Ainda, segundo a autora, as políticas públicas são ineficientes para solucionar as dificuldades educacionais, uma vez que "a educação de jovens e adultos, sempre é colocada à margem do processo educacional, tida como menos importante e até mesmo desnecessária” (Borges Neto, 2008, p. 7).

O fato é que as discussões sobre esse tema são complexas e, por isso, não esgotaremos essas discussões neste texto. 
Mas, partimos do princípio que somente promover o acesso aos estudantes da EJA não é suficiente: é necessário "capacitá-los para aquisição de novas competências, preparando-os para lidar com diferentes linguagens e tecnologias para responder aos desafios de novas dinâmicas e processos" (Piconez, 2002, p. 108). Para tal, objetiva-se, neste artigo, apresentar os resultados de um estudo em que analisamos as diferenças e convergências entre as duas modalidades no ensino de Química: EJA e o ER. Vale ressaltar, que o estudo delimita-se ao ensino de Química na $3^{\text {a }}$ série do Ensino Médio (EJA e ER).

\section{Marcos Histórico e Legal}

Diante dos marcos e do breve histórico que apresentaremos nessa seção, perceberemos que a EJA não pode ser considerada recente. De fato, os registros das primeiras intervenções educacionais envolvendo Jovens e Adultos, no Brasil, referem-se à educação missionária dos jesuítas, por isso ela "[...] perpassa a trajetória do próprio desenvolvimento da educação [...]" (Friedrich et al. 2010, p. 394). Em decorrência da industrialização, a década de 30 foi um divisor de águas para a educação de adultos, uma vez que era necessária mão de obra qualificada para atuar na indústria e, dessa maneira, foi preciso buscar alternativas para reduzir o analfabetismo, principalmente com os adultos trabalhadores (Sampaio, 2009). Desde então, muitas intervenções foram feitas com a finalidade de atender esse público.

Para compreendermos melhor a estrutura e funcionamento da EJA é necessário conhecer as Leis que embasam o surgimento e a manutenção dessa modalidade. Uma das primeiras medidas legais que fundamentam o ensino de adultos no país foi a Constituição Federal de 16 de Julho de 1934, que previa, em seu artigo 150, § único, alínea "a", um "ensino primário integral, gratuito e de frequência obrigatória, extensivo aos adultos" (Brasil, 1934, s/p.). Como podemos notar a necessidade de oferecer escolarização desse público já aparecia em textos normativos, como o da Constituição de 1934. Porém, é na década seguinte que a escolarização começaria a ganhar forma, por meio de iniciativas mais concretas, como menciona Strelhow (2010):

Desde o início da década de 40, a educação de jovens e adultos estava em alta. Em 1946 surge a Lei Orgânica do Ensino Primário que previa o ensino supletivo, e em 1947 surgiu um programa, de âmbito nacional, visando atender especificamente às pessoas adultas, com a criação do SEA (Serviço de Educação de Adultos) (Strelhow, 2010, p. 53).

A tendência em ofertar o benefício da escolarização de adultos, gerou muitas ações e programas governamentais a níveis estaduais e locais nos anos 40 e 50 e outros com abrangência nacional, como o "Fundo Nacional de Ensino Primário em 1942, o Serviço de Educação de Adultos e da Campanha de Educação de Adultos, ambos em 1947, a Campanha de Educação Rural iniciada em 1952 e a Campanha Nacional de Erradicação do Analfabetismo em 1958” (Di Pierro, Joia \& Ribeiro, 2001, p. 59).

De acordo com Di Pierro, Joia e Ribeiro, 2001 (p. 59), a Campanha de Educação de Adultos, sob a responsabilidade de Lourenço Filho em 1947, fez com que a União assumisse um papel indutor por meio da distribuição de fundos públicos para as iniciativas de estruturação dos serviços de educação primária para jovens e adultos. Desta maneira, foi viabilizada a "criação e permanência do ensino supletivo integrado às estruturas dos sistemas estaduais de ensino" (Di Pierro, Joia \& Ribeiro, 2001, p. 59). Apesar da Campanha de 1947 ter despertado para a reflexão sobre a educação de adultos, não promoveu nenhuma proposta metodológica específica para esses indivíduos.

No início dos anos 60, o trabalho de Paulo Freire com o seu método de alfabetização de adultos ganha adeptos dos grupos populares articulados a sindicatos e outros movimentos sociais. Surgem então, os programas do "Movimento de Educação de Base (MEB), Movimento de Cultura Popular do Recife, ambos iniciados em 1961, dos Centros Populares de Cultura da União Nacional dos Estudantes, entre outras iniciativas de caráter regional ou local" (Di Pierro, Joia \& Ribeiro, 2001, p. 60). 
Também em 1961 é sancionada a primeira Lei de Diretrizes e Bases (LDB) da educação brasileira, Lei nº 4.024/61 reservando um artigo para tratar da escolarização daqueles que não tiveram oportunidade de estudar na idade correspondente à série como menciona no Título IV, capítulo II, artigo 27:

O ensino primário é obrigatório a partir dos sete anos e só será ministrado na língua nacional. Para os que o iniciarem depois dessa idade poderão ser formadas classes especiais ou cursos supletivos correspondentes ao seu nível de desenvolvimento (Brasil, 1961, s/p.).

A LDB, 4.024/61, preconizava ainda, no seu artigo 99, que para:

[...] maiores de 16 anos será permitida a obtenção de certificados de conclusão do curso ginasial, mediante a prestação de exames de madureza, após estudos realizados sem observância de regime escolar. $\S$ único: Nas mesmas condições permitir-se-á a obtenção do certificado de conclusão de curso colegial aos maiores de 19 anos (Brasil, 1961, s/p.).

Até aquele momento, conforme mencionava a LDB, aqueles que não tivessem concluído o ensino fundamental [na ocasião, ginasial] até os 16 (dezesseis) anos e o ensino médio [colegial] com 19 (dezenove) anos, poderiam realizar exames de conclusão, estando eles em “classes especiais ou cursos supletivos” (Brasil, 1961, s/p.). Em 1964, foi organizado pelo Ministério da Educação, o Programa Nacional de Alfabetização de Adultos que contou com as orientações de Paulo Freire, mas com a repressão violenta do governo no período militar, esse e outros programas desapareceram e/ou desestruturaram-se (Strelhow, 2010).

Nesse ínterim, a Lei 5.379/67 cria o denominado Movimento Brasileiro de Alfabetização (Mobral), cujos intuitos eram extinguir o analfabetismo e promover a educação de adolescentes e adultos. Todavia, o programa tinha como objetivo, substituir a alfabetização utilizada pelos movimentos sociais antes do golpe. Embora o Mobral "baseava-se no aproveitamento das experiências significativas dos alunos" (Rybczynski 2014, p.1), divergia de Freire que pensava a alfabetização e a educação de jovens e adultos como meios formador de opinião, possibilitar criticidade ao indivíduo, opinante na sociedade, e, não que somente soubesse escrever e fosse fonte de obtenção de mão de obra. Para Rybczynski (2014) a principal diferença entre o Mobral e a proposta de Paulo Freire era,

“[...] o fato de no Mobral haver uma uniformização do material utilizado em todo o território nacional, não traduzindo assim a linguagem e as necessidades do povo de cada região, principal característica da metodologia freiriana" (Rybczynski, 2014, p.1).

Depois de vários debates ideológicos e sociais, e, entre outros motivos decorrentes da responsabilidade sobre a realização desses exames supletivos, foi promulgada a segunda Lei de Diretrizes e Bases da Educação Nacional (LDENB), $\mathrm{n}^{\circ}$ 5.692, publicada em 11 de agosto de 1971, especificando o atendimento de jovens e adultos no capítulo IV, artigo 24, alíneas "a" e "b":

a) suprir a escolarização regular para os adolescentes e adultos que não a tenham seguido ou concluído na idade própria; b) proporcionar, mediante repetida volta à escola, estudos de aperfeiçoamento ou atualização para os que tenham seguido o ensino regular no todo ou em parte (Brasil, 1971, s/p.).

Ainda de acordo com essa LDB, reduziu-se a idade mínima para realização dos cursos e exames supletivos: 15 anos, na conclusão do ensino fundamental; e 18 anos, do ensino médio (Brasil, 1971). A redução da idade mínima garantiu que os alunos ficassem menos tempo afastados das escolas. Essas medidas legais surgiam em meio à queda do regime militar, que provocaram mudanças políticas e sociais no Brasil, que apontavam para a volta da democracia e, nesse contexto, diante dos anseios populares a EJA continuou sendo pauta frequente nas leis. Uma das grandes conquistas para a modalidade foi à 
promulgação da Constituição Federal de 1988, que, em seu artigo 208, capítulo IV, § $1^{\circ}$, preconiza também que é dever do Estado garantir a gratuidade do ensino para de jovens e adultos.

Para que esse jovem e/ou adulto tenha a sua escolarização garantida, é necessário que ele tenha, também, um projeto de curso que leve em considerações as suas particularidades (Santos \& Ribeiro, 2020). Com efeito, o público da EJA é diversificado: trabalhadores/as, mães, pais, jovens excluídos por algum motivo durante o ER, entre outros fatores. Diante disso, foi acrescida à LDB de 1996, princípios para a EJA que preveem a "garantia do direito à educação e à aprendizagem ao longo da vida" (Brasil, 1996), propondo que os estudos desse público sejam continuados.

Ao tratar dessa continuidade dos estudos, as Diretrizes Curriculares Nacionais da Educação Básica (DCNEB), constata que a maioria dos estudantes noturnos, diferentemente dos diurnos, possui outras ocupações além dos estudos, o que pode levá-los a interrupção escolar. De fato, pode prejudicar o desempenho e, também, o envolvimento com o ambiente acadêmico (Abrantes, 2012, p. 9).

Quando voltamos nosso olhar para o ensino de química, essa falta de interesse e/ou estímulo podem ser ainda maior. De fato, muitas vezes os estudantes não veem significação no que é ensinado. Não conseguem associar os conteúdos ao seu dia a dia. Sendo assim, as disciplinas se tornam desinteressantes, uma vez que os professores repassam o conteúdo de forma mecanicista, desvinculando teoria da prática. Diante do breve histórico da EJA e das medidas legais que já foram adotadas até aqui, sabe-se que ainda há muito a ser feito para que haja equidade no ensino. O que não pode acontecer é a discriminação desse ensino, bem como a dos alunos que por ela passam.

\section{Metodologia}

A pesquisa é de natureza qualitativa que, segundo Godoy (1995), "tem o ambiente natural como fonte direta de dados e o pesquisador como instrumento fundamental" (p. 62). Nesse sentido André e Gatti (2010) ressaltam que esse tipo de pesquisa possibilita melhor compreensão dos processos de ensino-aprendizagem e corrobora para os avanços nos estudo em educação, aproximando o pesquisador do pesquisado:

[...] criando um compromisso maior com as necessidades e possibilidades de melhorias sócio-educacionais, por meio de intervenções diretas nas realidades pesquisadas ou pelo envolvimento nos debates e na formulação das políticas educativas (André \& Gatti, 2010, p. 9).

A pesquisa também se classifica como exploratória por "proporcionar maior familiaridade com o problema, com vistas a torná-lo mais explícito. [...] têm como objetivo principal o aprimoramento de ideias ou a descoberta de intuições" (Gil, 2002, p. 41) e documental por tratar de "[...] materiais que não receberam ainda um tratamento analítico, ou que ainda podem ser reelaborados de acordo com os objetos da pesquisa" (Gil, 2002, p. 45).

Como procedimentos técnicos a pesquisa dividiu-se em duas fases. A primeira contou com a análise dos Currículos de Referência do Estado de Goiás do EMR, acessado pelo portal da Secretaria de Estado de Educação, Cultura e Esporte (Seduce) e o Currículo da EJA, obtido na coordenação da Instituição de ensino em que a pesquisa foi realizada.

$\mathrm{Na}$ segunda fase, desenvolveu-se os instrumentos para a coleta de dados. Foram elaborados e aplicados questionários, que se referem ao "conjunto de questões que são respondidas por escrito pelo pesquisado" (Gil, 2002, p. 114), e entrevistas semiestruturadas, que por sua vez, apresenta uma proposta de roteiro para a entrevista, mas sem a necessidade de seguir com rigidez esse roteiro (Gil, 2002, p. 115). Ou seja, a entrevista semiestruturada permite que os participantes [tanto pesquisador quanto o entrevistado] façam perguntas fora do que havia sido planejado.

Esses instrumentos foram aplicados junto aos estudantes, professores e coordenadores da 3 . $^{\mathrm{a}}$ série da EJA e também aos estudantes, dessa mesma série, do EMR. Tanto os questionários quanto as entrevistas tiveram a finalidade de analisar os 
motivos que levaram os estudantes a escolherem a modalidade que estudam, assim como verificar, também, o perfil sóciohistórico e econômico deles. Faz-se importante ressaltar que todos os envolvidos da pesquisa formalizaram a concordância em participação por meio do Termo de Consentimento Livre e Esclarecido (TCLE).

Em relação ao questionário aplicado para aos estudantes e professores de química, serviu para levantar dados sobre essas duas realidades no que se refere ao ensino de Química, proporcionando a análise comparativa das modalidades em questão. Já as entrevistas realizadas com os(as) professores(as) e coordenadores(as) do EMR e da EJA, serviram para complementar os dados coletados por meio dos questionários. Após o desenvolvimento das fases da pesquisa, os dados foram consolidados e analisados onde serão apresentados a seguir.

\section{Resultados e Discussão}

Apresentar e discutir os interferentes relacionados à EJA e ao EMR no ensino de Química torna-se imprescindíveis para a (re)construção de um novo olhar sobre essas duas modalidades do ensino. Para a coleta de dados, foram elaborados e aplicados questionários aos alunos da EJA e do EMR.

O instrumento é formado por 22 (vinte e duas) questões, sendo que, na primeira parte, faz um levantamento sobre o perfil sócio-histórico, delineando o perfil dos alunos participantes da pesquisa.

A aplicação contou com a participação de 96 estudantes, sendo 23 são da EJA e 73 do EMR, como é apresentado na Tabela 1.

Tabela 1: Perfil das turmas da EJA e do Ensino Médio Regular (EMR).

\begin{tabular}{c|c|c|c|c|c|c|c|c|c}
\hline \multirow{2}{*}{$\begin{array}{c}\text { ETAPA/SÉRIE } \\
\text { Modalidade }\end{array}$} & \multicolumn{3}{|c|}{ TURMAS } & $\begin{array}{c}\text { Quanti- } \\
\text { dade }\end{array}$ & \multicolumn{2}{c|}{ SEXO } & \multicolumn{3}{c}{ ESTADO CIVIL } \\
\cline { 2 - 10 } & A & B & C & & F & M & $\begin{array}{c}\text { Soltei- } \\
\text { ro(a) }\end{array}$ & $\begin{array}{c}\text { Casa- } \\
\text { do(a) }\end{array}$ & $\begin{array}{c}\text { Não } \\
\text { respondeu }\end{array}$ \\
\hline $\begin{array}{c}3^{\text {o }} \text { semestre - } \\
\text { EJA }\end{array}$ & 23 & - & - & 23 & 12 & 11 & 71 & 2 & - \\
\hline $3^{\text {a }}$ série -EMR & 24 & 24 & 25 & 73 & 49 & 24 & 19 & 3 & 1 \\
\hline
\end{tabular}

Fonte: Autores.

Conforme dados apresentados na Tabela 1, percebe-se que apesar da pequena diferença na EJA, a maioria dos alunos das duas modalidades, é do sexo feminino. Outro fator que não apresenta diferença significativa foi em relação ao Estado Civil, pois nas duas modalidades apenas uma pequena parcela dos alunos são “casados". Porém, o que se destaca, é que o maior número está no EMR.

Quanto à faixa etária, o levantamento apontou a prevalência de maior concentração de estudantes em duas faixas etárias, como pode ser visto na Tabela 2. 
Tabela 2: Faixa etária dos discentes, por modalidade de ensino.

\begin{tabular}{c|c|c|c|c|c}
\hline \multirow{2}{*}{$\begin{array}{c}\text { ETAPA/SÉRIE } \\
\text { MODALIDADE }\end{array}$} & \multicolumn{4}{|c|}{ FAIXA ETÁRIA } & \multirow{2}{*}{$\begin{array}{c}\text { Não } \\
\text { respondeu }\end{array}$} \\
\cline { 2 - 6 } & $\mathbf{1 7}$ à $\mathbf{1 9}{ }^{1}$ & $\mathbf{2 0}$ à $\mathbf{2 2}$ & $\mathbf{2 3}$ à 28 & $\mathbf{3 0}$ à 44 & 0 \\
\hline $\begin{array}{c}\mathbf{3}^{\mathbf{0}} \text { semestre da 3 } \\
\text { EJA Etapa - }\end{array}$ & 2 & 12 & 4 & 5 & 1 \\
\hline $\mathbf{3}^{\text {a }}$ série - E. M. R & 66 & 6 & 0 & 0 & \\
\hline
\end{tabular}

Fonte: Autores.

Nota-se que a maior quantidade de alunos da EJA está na faixa etária de 20 a 22 anos, enquanto os do EMR estão entre 17 a 19 anos. Verifica-se que, embora alguns autores considerem a EJA como uma modalidade composta por poucos jovens, como Lima e Silva (2013, p. 457), que dizem que, “[...] a população da EJA hoje é composta por sua grande maioria de adultos e idosos e bem poucos jovens", os dados coletados mostram o contrário. Não há grande discrepância entre as idades. Dos 23 estudantes, 14 estão entre 18 e 22 anos, cinco têm entre 30 e 44 anos e um aluno não respondeu. Assim, o público participante da pesquisa na escola campo pode ser considerado jovem.

Outro fator analisado foi à relação entre trabalho e estudo. Visando delinear o perfil dos estudantes da EJA e do EMR, apresenta-se na Tabela 3, a quantidade de estudantes que se enquadram em cada categoria.

Tabela 3: Alunos que trabalham e estudam, por modalidade de ensino.

\begin{tabular}{c|c|c|c}
\hline $\begin{array}{c}\text { ETAPA/SÉRIE } \\
\text { MODALIDADE }\end{array}$ & $\begin{array}{c}\text { APENAS } \\
\text { ESTUDAM }\end{array}$ & $\begin{array}{c}\text { ESTUDAM E } \\
\text { TRABALHAM }\end{array}$ & $\begin{array}{c}\text { NÃO } \\
\text { RESPONDEU }\end{array}$ \\
\hline $3^{\text {o }}$ semestre da $3^{\text {a }}$ Etapa - EJA & 3 & 20 & - \\
\hline $3^{\text {a }}$ série - E. M. R & 45 & 28 & 01 \\
\hline
\end{tabular}

Fonte: Autores.

Identificou-se que no EMR, 45 estudantes “apenas estudam", enquanto 28 "estudam e trabalham". Nota-se que $61 \%$ dos estudantes no EMR dedicam-se somente aos estudos. Na EJA o resultado foi inverso: apenas três estudantes "somente estudam", enquanto a maioria, aproximadamente $87 \%$, “estudam e trabalham”. Esse resultado confere o que outras pesquisas, como Di Pierro e Haddade (2000) e Santos, Rodrigues-Filho e Amauro (2016) já apontavam: na EJA tem-se predominantemente a grande parte de estudantes trabalhadores. E, de fato, analisando essa modalidade em uma linha do tempo histórica, podemos perceber que essa modalidade continua tendo, em sua grande maioria, estudantes trabalhadores.

Se analisarmos o número de alunos que trabalham com a faixa etária apresentada: 20 à 22 (12 alunos), 23 à 28 (04 alunos), 30 a 44 (05 alunos), especificados na Tabela 2, verifica-se que, a somatória totaliza 21 (vinte um) alunos. Assim, conclui-se que apenas 01 (um) aluno dessas faixas etárias e 02 (dois) na faixa etária de 18 à 19 anos “apenas estudam”.

Desta maneira, o perfil dos alunos da EJA vai de encontro com a legislação, uma vez que apontam uma proposta pedagógica para alunos trabalhadores. Por esse motivo, a organização dos estudos, conforme a Resolução CEE/GO, $\mathrm{n}^{\circ}$ 08/2016, descreve no artigo 10, que “o horário das atividades adaptar-se-á, na medida do possível, ao tempo disponível do aluno trabalhador, de acordo com a realidade de cada localidade" (CEE/GO 2016, s/p.).

Ao que se refere ao perfil econômico dos alunos das duas modalidades, apresenta-se a descrição a seguir:

\footnotetext{
${ }^{1}$ Os dois estudantes da EJA possuem 18 e 19 anos de idade, respectivamente. Utilizou-se este intervalo de 17 a 19 anos para facilitar o agrupamento das faixas etárias, uma vez que, no EMR há 24 alunos com 17 anos e foi necessário contabilizá-los.
} 
Tabela 4: Renda média familiar por modalidade de ensino.

\begin{tabular}{c|c|c}
\hline \multirow{2}{*}{ RENDA MÉDIA FAMILIAR } & \multicolumn{2}{|c}{ QUANTIDADE DE ALUNOS } \\
\cline { 2 - 3 } & EJA & EMR \\
\hline Menor que 1 salário mínimo & 5 & 6 \\
\hline Entre 1 e 2 salários mínimos & 11 & 40 \\
\hline Entre 2 e 3 salários mínimos & 5 & 13 \\
\hline Acima de 3 salários mínimos & 1 & 12 \\
\hline Não responderam & 1 & 2 \\
\hline
\end{tabular}

Fonte: Autores.

Os resultados apresentados na Tabela 4 mostram que nas duas modalidades de ensino, a renda média familiar que prevalece, em sua maioria, fica na faixa de 1 a 2 salários mínimos.

Apesar da maioria dos alunos da EJA possuir um número maior de alunos trabalhadores, a renda média é equivalente a dos alunos do EMR. Tanto na EJA quanto no EMR, menos da metade (08 alunos da EJA e 27 alunos do EMR), está concentrada nas rendas acima de dois salários mínimos.

Conforme Barreto (2006), a entrada precoce no mercado de trabalho e as experiências sociais tornam o aluno da EJA com saberes enriquecedores que os auxiliaram a intervir no meio em que vivem (Barreto, 2006, p. 8). Contudo, a necessidade de trabalhar pode ser um dos fatores que levem os alunos a abandonar os estudos, como menciona Bausanelli (2012):

Falta de interesse nos estudos; pretensão de um emprego para ajudar à família; gravidez precoce (desejada ou não); falta de condições especiais para o deficiente - qualquer que seja sua deficiência; falta, ou pouco, incentivo da família aos estudos; a falta de compreensão da importância dos estudos [...] São vários os motivos que fazem adolescentes e jovens desistirem ou abandonarem o ensino básico na idade regular (Bausanelli, 2012, p. 5).

Por esses motivos é que a própria proposta pedagógica das escolas que oferecem a EJA devem promover um ensino que leve em consideração as particularidades dos estudantes, despertando a permanência desses alunos. No entanto, nem sempre isso acontece. Na entrevista com a Coordenadora da EJA do CENCAC, denominada como "Coordenadora A (CA)" , faz essa relação entre o trabalho e as causas da evasão escolar, tanto no EMR, como na EJA:

Olha, na Educação de Jovens e Adultos a evasão ela é bem maior. No Ensino Médio Regular nem tanto, porque os alunos eles são mais jovens, são adolescentes e acaba que a família acaba influindo um pouco mais. Mesmo que eles queiram a família não deixa. Então, acontece sim, uma ou outra evasão, mas, na Educação de Jovens e Adultos essa evasão é um pouco significativa, principalmente considerando que todos os alunos que cursam essa etapa, que é o Ensino Médio, eles tem que ter acima de 18 anos, então são responsáveis pelos próprios atos, e como eu disse anteriormente, são alunos trabalhadores, a maioria deles são arrimos de família e acabam tendo que trabalhar para sustentar a família, e por muitas vezes não conseguem conciliar o trabalho com a escola e acabam deixando a escola, mas a gente faz um trabalho de entrar em contato para fazer com que eles retornem, alguns a gente até consegue e outros, nem sempre, mas evasão na EJA é bem maior e eu considero que esse é o motivo principal (CA, 2018).

Segundo o relato da CA, considera-se que o principal motivo do número de alunos da EJA ser menor do que o EMR é por causa da evasão. O fato dos alunos precisarem trabalhar e estudar, como foi mostrado na Tabela 3, favorece a desistência dos estudos. Ao cogitar uma porcentagem de evasão, declara: "olha, eu posso te dizer que cerca de 30\%" (CA, 2018). Apesar dessa afirmação, vale ressaltar que essa afirmativa é apenas uma observação pessoal da coordenadora entrevistada e não é objeto principal desta pesquisa.

Ao que se refere à literatura, a responsabilidade de auxiliar na complementação da renda familiar pesa na decisão de permanência na escola como mencionado por Bausanelli (2012).

Di Pierro (2010) relata que não é somente o trabalho que desmotiva os alunos da EJA a permanecerem nas escolas, 
segundo o autor o que ocorre é que:

[...] os conteúdos veiculados são pouco relevantes e significativos para tornar a frequência escolar atrativa e motivadora para pessoas cuja vida cotidiana já está preenchida por compromissos imperiosos e múltiplas exigências sociais (Di Pierro, 2010, p.15).

Inclusive, como mencionado acima, o tempo de afastamento dos alunos do colégio pesquisado também pode ter ligação direta com os fatores "trabalho" e "currículo atrativo".

Na Tabela 5, a seguir, especifica-se o tempo desses alunos fora da escola.

Tabela 5: Tempo de afastamento dos estudos pelos alunos EJA.

\begin{tabular}{c|c}
\hline TEMPO FORA DA ESCOLA & QUANTIDADE DE ALUNOS \\
\hline 6 meses à 1 ano & 5 \\
\hline 2 anos & 8 \\
\hline 3 à 20 anos & 8 \\
\hline
\end{tabular}

Fonte: Autores.

Como apontam os resultados, a maior concentração de afastamento está nos períodos de 2 (dois) anos e de 3 (três) à 20 (vinte) anos, por apresentarem a mesma quantidade. Isso nos remete a um público diversificado pois essa diferença significativa entre o tempo de afastamento também está relacionada com a idade. Esse dado justifica-se a partir da Tabela 2 que mostra a faixa etária dos alunos da EJA que, em sua maioria, vai de 20 à 44 anos. Essa característica de diversidade etária e tempo de permanência na escola exige um ensino significativo e não mecanicista, principalmente ao que se refere ao ensino da química.

De acordo com Villela e Archangelo (2013, p. 57), o ensino significativo está ligado diretamente a escola significativa, ou seja, "é aquela cujos atos de ser façam sentido para o aluno e favoreçam a expansão e a ressignificação de suas experiências, ampliando a curiosidade e seu interesse pelo mundo". E, a partir do momento em que a escola desenvolve esse trabalho forma uma "[...] dupla: o ensino significativo é o desdobramento da escola significativa [...]".

Conforme a proposta de Freire, citado por Baquero (2008, p. 155), a compreensão da educação deve ser tratada "como um ato político; como um ato de conhecimento e não como uma simples transferência de conhecimento; como um conhecimento dialógico no descobrimento rigoroso da razão de ser das coisas [...]”. Por esse motivo, que é imprescindível que, não apenas a EJA, mas todas as modalidades de ensino, pensem em fazer o ensino significativo, pois ele "tende a ser pensado como aquele que se ajusta às necessidades cognitivas e afetivas do aluno. [...] promove a aprendizagem significativa, em oposição à aprendizagem mecânica, desarticulada, sem sentido ou mesmo descartável” (Villela; Archangelo, 2013, p. 57).

Em relação aos fatores que os levaram os alunos a frequentar a EJA e não o EMR, os discentes do $3 .^{\circ}$ semestre, da $3^{\mathrm{a}}$ etapa da EJA, apontaram 5 (cinco) motivos predominantes, como mostra o Quadro 1. 
Quadro 1: Demonstrativo dos fatores motivacionais para o ingresso na EJA.

\begin{tabular}{|c|c|c|}
\hline $\mathbf{N}^{\mathbf{o}}$ & FATORES MOTIVACIONAIS & $\begin{array}{l}\text { QUANTIDADE } \\
\text { DE ALUNOS }\end{array}$ \\
\hline 1. & Conseguir um trabalho melhor & 08 \\
\hline 2. & 1) Necessidade de possuir o Ensino Médio & 08 \\
\hline 3. & Concluir os estudos rapidamente & 04 \\
\hline 4. & Devido ao horário de trabalho & 09 \\
\hline 5. & Desejo de cursar o Ensino Superior & 06 \\
\hline
\end{tabular}

Fonte: Questionários (2018/2).

O Quadro 1 mostra que os alunos responderam mais de uma alternativa, indo de encontro com seu grau de interesse e situação atual. Os maiores números de respostas foram dispostas nos fatores relacionados a "horário de trabalho", perspectiva de "trabalho melhor" e "necessidade de ter o ensino médio". Apesar de terem como motivação o mercado de trabalho, apenas 06 (seis) tem interesse em continuar os estudos, como mostra o item 5.

A quantidade de respostas relacionadas aos fatores: 1, 2 e 4, confirmam que isso acontece devido à maioria "trabalhar e estudar", conforme dados apresentados na Tabela 3. Outro fator que chama atenção é a quantidade de respostas sobre o interesse em "concluir rapidamente os estudos". Apenas 04 (quatro) alunos marcaram esta alternativa demonstrando a ideia errônea que se faz sobre o ingresso desses indivíduos nesta modalidade de ensino.

Ao compararmos com o EMR, segundo Souza e Vazquez (2015), a perspectiva para o mercado de trabalho e o desinteresse pelo ingresso no ensino superior é a mesma que os alunos da EJA:

[...] os jovens de escolas públicas possuiriam baixa expectativa de continuidade dos estudos em geral (e de ingresso no ensino superior em particular, especialmente na universidade pública) e alta expectativa com relação ao ingresso no mercado de trabalho (Souza \& Vazquez, 2015, p.14).

Apesar da maioria dos alunos da EJA "trabalharem e estudarem", os alunos do EMR também possuem as mesmas expectativas, ou seja, "o trabalho se imporia como uma necessidade (para contribuir com a renda familiar)" (Souza \& Vazquez, 2015, p.14). Apesar disso, como mencionam Souza e Vazquez (2015, p. 414), esses alunos permanecem estudando porque “a interrupção da trajetória educacional seria uma fatalidade (por conta da impossibilidade de conciliar trabalho e estudo, da dificuldade de ingressar na universidade pública ou de pagar uma mensalidade em uma faculdade privada)".

Esse grau de dificuldade e falta de expectativa para o ingresso nos cursos superiores reflete também na relevância das disciplinas. Mesmo que haja uma pequena parcela de alunos da EJA e do EMR que pretendem ingressar em cursos superiores, conseguem ver a necessidade de aprendizado nas ciências da natureza, neste caso específico, a "química".

Quando os alunos foram questionados se a química é importante, dos 96 (noventa e seis) alunos (EMR e EJA), 95 (noventa e cinco) disserem que "sim". Dentre estes, apenas 1 (um) aluno "não respondeu".

O interesse desses alunos em relação à disciplina mostrou-se "mediano" como pode ser visto na Tabela 6, abaixo:

Tabela 6: Interesse pela disciplina de Química.

\begin{tabular}{c|c|c}
\hline \multirow{2}{*}{$\begin{array}{c}\text { Nível de interesse } \\
\text { Pela química }\end{array}$} & \multicolumn{2}{|c}{ Quantidade de alunos } \\
\cline { 2 - 3 } & EJA & EMR \\
\hline Nenhum & 03 & 05 \\
\hline Pouco & 03 & 13 \\
\hline Médio & 14 & 42 \\
\hline Muito & 03 & 13 \\
\hline
\end{tabular}

Fonte: Autores. 
Segundo Zucco (2011, p. 1), em sua obra “Química para um mundo melhor”, a química é responsável pela evolução de todos os ramos do conhecimento e, sem a qual, o mundo que conhecemos não teria materiais sintéticos e, portanto, "a vida, hoje, seria chata, curta e dolorida". O autor continua dizendo que:

É evidente que a Química tem na natureza sua fonte de matéria e de inspiração. Entretanto, é responsabilidade do ser humano o avanço para além do que é natural no universo. Por isso, a celebração da Química só se completa com a celebração das pessoas, daqueles verdadeiros artífices da fantástica arte da transformação da matéria. Celebrar a Química é incentivar crianças e jovens a se tornarem químicos e serem capazes de, literalmente, transformar a matéria em novidades! É desafiá-los a se envolverem com as especialidades e as tecnologias da Química direcionadas à manufatura de produtos para melhorar o bem-estar da humanidade (Zucco, 2011, p.1).

Conforme os dados mostrados na Tabela 6, percebe-se que diante da importância da Química, apenas 13 (treze) alunos do EMR e 3 (três) alunos da EJA tem "muito interesse" pela disciplina.

Observa-se que, o número de alunos que responderam "nenhum" ou "pouco", totalizam 06 (seis) dos 14 (quatorze) alunos da EJA e, 18 (dezoito) dos 42 (quarenta e dois) alunos do EMR, ou seja, totalizam quase a metade dos alunos das duas modalidades que responderam ter interesse "médio" na disciplina.

Segundo Cardoso e Colinvaux (2000), essa falta de interesse em Química por parte dos alunos se justifica pela quantidade excessiva de conteúdos abstratos, teóricos e sem a real aplicação no cotidiano. Podemos reafirmar o exposto ao verificarmos os dados apresentados na Tabela 7.

Tabela 7: Compreensão dos conteúdos e tempo para o aprendizado.

\begin{tabular}{c|c|c|c|c|c}
\hline \multirow{2}{*}{$\begin{array}{c}\text { ETAPA/SÉRIE } \\
\text { MODALIDADE }\end{array}$} & \multicolumn{4}{|c}{$\begin{array}{c}\text { QUANTIDADE DE ALUNOS } \\
\text { COMPREEDEM O } \\
\text { CONTEÚDO }\end{array}$} & $\begin{array}{c}\text { O TEMPO É } \\
\text { SUFICIENTE PARA O } \\
\text { APRENDIZADO }\end{array}$ \\
\cline { 2 - 6 } & SIM & NÃO & $\begin{array}{c}\text { ÀS } \\
\text { VEZES }\end{array}$ & SIM & NÃO \\
\cline { 2 - 6 } & 7 & 0 & 16 & 11 & 12 \\
\hline $3^{\circ}$ Semestre da 3 ${ }^{\text {Etapa - EJA }}$ & 34 & 0 & 39 & 52 & 21 \\
\hline $3^{\text {a }}$ série - EMR & & &
\end{tabular}

Fonte: Autores.

Ao analisarmos a Tabela 7, observa-se que a compreensão do conteúdo de mais da metade dos alunos da EJA só acontece "às vezes", divergindo das respostas colocadas a seguir, pois quando questionados sobre o "tempo ser suficiente para o aprendizado", as respostas "negativas" tiveram uma margem mínima de diferença, apenas de 01 (um) aluno, em relação aos que responderam que "sim". Foram 11 (onze) "sim" e apenas 12 (doze) "não".

Em relação ao EMR, apesar da maioria, 39 (trinta e nove) alunos terem respondido "às vezes", a margem de diferença em relação aos que responderam "sim”, 34 (trinta e quatro), foi pouco significativa, ou seja, apenas 05 (cinco) alunos a mais compreendem "às vezes" os conteúdos.

Apesar de não ser um número muito significativo para o esperado, as respostas corroboram com o "tempo de aprendizado", uma vez que 52 (cinquenta e dois) alunos disseram "ser suficiente" e 21 (vinte e um) disseram que "não é suficiente" para o aprendizado de química.

\section{Considerações Finais}

Por meio dos dados coletados nessa pesquisa, constata-se que o público da EJA pode ser considerado jovem, porém 
ainda tem faixa etária maior que a dos alunos do EMR. A maioria é do sexo feminino, trabalhadores(as) e estudantes, que possuem renda média familiar baixa e equivalente à dos alunos do EMR, o fato da maioria dos alunos EJA trabalharem e ainda assim possuírem renda baixa, demonstra a responsabilidade que possuem diante da complementação de renda e/ou sustento de suas famílias.

Essa responsabilidade, somada a fatores como: excesso de conteúdos e falta de tempo para aprofundá-los, predomínio do modelo tradicionalista de ensino, no qual há aulas teóricas em detrimento a aulas práticas, ausência de experimentação, ensino memorístico, contextualização, laboratório em desuso, e, falta de adesão as TICs para o ensino, provocam nos alunos da Educação de Jovens e Adultos uma maior rejeição e/ou falta de interesse pela química, se comparado aos discentes do Ensino Médio Regular.

Além da redução de carga horária e da inexistência de um material didático apropriado na EJA, nessa modalidade ainda deixam de ser abordada a parte macroscópica de conteúdos científicos [e que se fazem presente no cotidiano dos estudantes]. A inexistência destas discussões deixa de promover uma consciência crítica em relação à gestão dos recursos do meio ambiente e impacto sobre as futuras gerações. Dessa forma, é importante que pesquisas futuras investiguem, também, possibilidades de materiais didáticos específicos para a EJA, levando em consideração as particularidades dessa modalidade de ensino.

A pesquisa alcançou o objetivo de efetuar um estudo comparativo entre a EJA e o EMR, levando-nos à compreensão de como ocorre o ensino da química. Por fim, corrobora-se a hipótese de que o ensino propedêutico ainda acontece no contexto da educação básica. É evidente a necessidade de maior foco na EJA, no seu currículo e nas ações pedagógicas desenvolvidas nesta modalidade, conforme mostram Vasques e Messeder (2020). Como menciona Freire (1996, p. 24), "é na inconclusão do ser, que se sabe como tal, que se funda a educação como processo permanente" e a EJA deve ser visto como tal.

\section{Referências}

Abrantes, N. N. F. (2012). Trabalho e estudo: uma conciliação desafiante. IV FIPED.

André, M. \& Gatti, B.A. (2010). Métodos Qualitativos de Pesquisa em Educação no Brasil: origens e evolução. Vozes.

Baquero, R. (2008). Educação de adultos. Autêntica.

Barreto, E. C. V. (2006). Trabalhando com a Educação de Jovens e Adultos: A Sala de Aula como espaço de vivência e aprendizagem. Secad.

Bausanelli, A. P. (2012). Aprendizagem de jovens e adultos: a aprendizagem a seu tempo. São Paulo: Uniasselv.

Borges Neto, F. A. (2008). Geografia escolar do aluno EJA: caminhos para uma prática de ensino. Dissertação de Mestrado em Geografia. Universidade Federal de Uberlândia, Uberlândia, MG, Brasil.

Brasil. (1934). Ministério da Educação. Constituição Federal de 1934. https://www.jusbrasil.com.br/topicos/10616954/artigo-150-da-constituicao-federal-de16-de-julho-de-1934

Brasil. (1961). Ministério da Educação e Cultura. Lei de Diretrizes e Bases da Educação Nacional, 1961. <http://www2.camara.leg.br/legin/fed/lei/19601969/lei-4024-20-dezembro-1961-353722-publicacaooriginal-1-pl.html

Brasil. (1971). Ministério da Educação e Cultura. Lei de Diretrizes e Bases da Educação Nacional, 1971. <http://www2.camara.leg.br/legin/fed/lei/19701979/lei-5692-11-agosto-1971-357752-publicacaooriginal-1-pl.html>

Brasil. (1988). Senado Federal. Constituição Federal de 1988. <https://www2.senado.leg.br/bdsf/bitstream/handle/id/518231/CF88_Livro_EC91_2016.pdf>

Brasil. (1996). Ministério da Educação e Cultura. Lei de Diretrizes e Bases da Educação Nacional, 1996. <ftp://ftp.fnde.gov.br/web/siope/leis/LDB.pdf>

Brasil. (2000). Ministério da Educação. Conselho Nacional de Educação. Parecer CNE/CEB 11/2000. <http://portal.mec.gov.br/cne/arquivos/pdf/pceb011_00.pdf>

Cardoso, S. P. \& Colivaux, D. Explorando a Motivação para Estudar Química. Química Nova, 23(3), 401-404.

CEE/GO. (2016). Resolução CEE/CP N.8. < http://www.sgc.goias.gov.br/upload/arquivos/2016-12/2016-08-cp-resolucao.pdf>

Di Pierro, M. C. \& Haddad, S. (2000). Escolarização de jovens e adultos. Revista Brasileira de Educação, 14, 108-130. 
Research, Society and Development, v. 10, n. 15, e69101522596, 2021

(CC BY 4.0) | ISSN 2525-3409 | DOI: http://dx.doi.org/10.33448/rsd-v10i15.22596

Di Pierro, M. C. (2010). Balanço e desafios das políticas públicas de educação de jovens e adultos no Brasil. Endipe.

Di Pierro,M. C.; Joia, O. \& Ribeiro, V. M. (2001). Visões da educação de jovens e adultos no Brasil. Cadernos Cedes, 55, 58-77.

Freire, P. (1996). Pedagogia da autonomia: Saberes necessários a prática educativa. (25a ed.), Paz e Terra.

Friedrich, M.; Benite, A. M. C.; Benite, C. R. M. \& Pereira, V. S. (2010). Trajetória da escolarização de jovens e adultos no Brasil: de plataformas de governo a propostas pedagógicas esvaziadas. Ensaio: Aval. Pol. Públ. Educ., 18 (67), 389-410.

Gil, A. C. (2002). Como Elaborar Projetos de Pesquisa. (4a ed. Atlas.

Godoy, A. S. (1995). Introdução à pesquisa qualitativa e suas possibilidades. Revista de Administração de Empresas, 35 (2), 57-63.

Lambach, M. \& Marques, C. A. (2009). Ensino de Química na Educação de Jovens e Adultos: Relação Entre Estilos de Pensamento e Formação Docente. Investigações em Ensino de Ciências, 14, 219-235.

Lima F. O. \& Silva N. R. (2013). O Perfil dos Alunos da Educação de Jovens e Adultos hoje: tempos de inclusão. Londrina: atas do VIII EBPEE.

Piconez, S. C. B. (2002). Educação Escolar de Jovens e Adultos. Campinas, SP: Papirus.

Rybczynski, E. (2014). Mobral, o ensino da ditadura. São Paulo: Leia as histórias. <http://saopaulominhacidade.com.br/his toria/ver/9064/Mobral\%252C\%2Bo\%2Bensino\%2Bda\%2Bditadura

Sampaio, M. N. (2009). Educação de Jovens e Adultos: Uma história de complexidade e tensões. UFSC.

Santos, J. P. V.; Rodrigues-Filho, G.; \& Amauro, N. Q. (2016). A Educação de Jovens e Adultos e a Disciplina de Química na Visão dos Envolvidos. Revista Química Nova na Escola, 38 (3), 244-250.

Santos, M. I. A. dos, \& Ribeiro, A. P. de M. (2020). O ensino-aprendizagem na educação de jovens e adultos e a teoria da reprodução de Bourdieu. Research, Society and Development, 9(3), 1-15.

Souza, D. C. C. \& Vazquez, D. A. (2015). Expectativas de jovens do ensino médio público em relação ao estudo e ao trabalho. Educação e Pesquisa, 41 (2), 409-426.

Strelhow, T. B. (2010). Breve História Sobre a Educação de Jovens e Adultos no Brasil. Revista Histedbr On-line, 38, 49-59.

Vasques, C. C., \& Messeder, J. C. (2020). Educação Ambiental em uma perspectiva reflexiva na Educação de Jovens e Adultos. Research, Society and Development, $9(8)$, e113984782.

Villela, F. C.B. \& Archangelo, A. (2013). Fundamentos da escola significativa. Loyola.

Zucco, C. (2011). Química para um mundo melhor. Química Nova na Escola, 34 (5), 733-734. 